Disponível em:

http://editora.unoesc.edu.br/index.php/race

RACE, Joaçaba, v. 17, n. 2, p. 475-506, maio/ago. 2018

\title{
RELAÇÃO DAS VARIÁVEIS DE DESEMPENHO E CONTROLE COM A DISTRIBUIÇÃO DE RIQUEZA DAS EMPRESAS LISTADAS NA BM\&FBOVESPA NO PERÍODO DE 2010 A 2015
}

\begin{abstract}
Relationship of performance and control variables to the distribution of wealth of the companies listed on the BM\&FBovespa in the period 2010 to 2015
\end{abstract}

Débora Adriana Zwicker Kiefer

E-mail: deboraadrianazwicker@gmail.com

Graduada em Ciências Contábeis pela Universidade do Estado de Santa Catarina; Especializanda em Gestão Financeira e Controladoria no Centro Universitário para o Desenvolvimento do Alto Vale do Itajaí; Auxiliar Administrativo na Empresa Siga Bem Distribuidora de Lubrificantes Ltda. de Rio do Sul.

Lara Fabiana Dallabona

E-mail: lara.dallabona@udesc.br

Doutora em Ciências Contábeis e Administração pela Fundação Universidade Regional de Blumenau; Mestre em Ciências Contábeis pela Fundação Universidade Regional de Blumenau; Professora no Curso de Ciências Contábeis da Universidade do Estado de Santa Catarina. Endereço para contato: Rua Getúlio Vargas, 2822, Bela Vista, 89140-000, Ibirama, Santa Catarina, Brasil.

Marilei Kroetz

E-mail: marilei.kroetz@udesc.br

Mestre em Economia pela Universidade Federal de Santa Catarina; Doutoranda em Economia no Instituto Superior de Economia e Gestão da Universidade de Lisboa, Portugal; Professora no Curso de Ciências Contábeis da Universidade do Estado de Santa Catarina.

Artigo recebido em 02 de dezembro de 2017. Aceito em 01 de maio de 2018. 


\section{Resumo}

Os indicadores de desempenho e de controle são alguns fatores que podem influenciar a distribuição de riqueza. Nesse contexto, neste trabalho teve-se como objetivo avaliar a relação das variáveis de desempenho e de controle com a distribuição de riqueza gerada e distribuída pelas empresas dos diferentes setores da Bovespa. A amostra compreende 268 empresas, dividas em nove setores econômicos. Para a tabulação dos dados, fez-se uso de planilhas eletrônicas do Microsoft Excel. Para a análise dos dados se utilizou a estatística descritiva e correlação canônica com utilização do software estatístico SPSS. Foi possível concluir que há relação entre as variáveis de desempenho e de controle com a geração e distribuição de riqueza das empresas da BM\&FBovespa, sendo que algumas estão mais fortemente associadas do que outras. As variáveis liquidez seca, liquidez corrente, imobilização do patrimônio líquido e tamanho estão fortemente associadas com a distribuição total. A distribuição para pessoal possui forte associação com as variáveis liquidez corrente e liquidez geral, as quais possuem forte relação também com a distribuição para impostos, taxas e contribuições. A distribuição para capital de terceiros, por sua vez, está associada com a imobilização do patrimônio líquido e a liquidez seca. Por fim, ao saber da forte relação das variáveis de desempenho com a DVA, confirma-se a hipótese de que as informações devem ser analisadas em conjunto para a tomada de decisões.

Palavras-chave: DVA. Desempenho. Indicadores.

\section{Abstract}

The indicators of performance and control are some factors that can influence the distribution of wealth. In this context, the aims of this study is to evaluate the relationship between performance and control variables with the distribution of wealth generated and distributed by companies in the different sectors of Bovespa. The sample comprises 268 companies, divided into 9 economic sectors. To tabulate the data the study made use of Microsoft Excel spreadsheets. Data analysis was performed using descriptive statistics and canonical correlation using SPSS statistical software. It was possible to conclude that there is a relation between the performance and control variables with the generation and distribution of wealth of BM\&FBovespa companies, some of which are more strongly associated than others. The distribution for personnel has a strong association with the current liquidity and general liquidity variables, which are also strongly related to the distribution of taxes, duties and contributions. The distribution to thirdparty capital, in turn, is associated with the immobilization of shareholders' equity and dry liquidity. Finally, knowing the strong relationship of performance variables with DVA, confirms the hypothesis that information should be analyzed together for decision-making.

Keywords: DVA. Performance. Indicators. 


\section{INTRODUÇÃO}

A contabilidade é uma ciência social que busca transformar dados referentes ao patrimônio das entidades em relatórios que auxiliem os seus usuários, sejam eles internos, sejam externos da empresa, na tomada de decisão (MARION, 2011). Machado, Macedo e Machado (2015) descrevem três características essenciais da contabilidade, sendo a primeira a contribuição da informação contábil para a diminuição da diferença de informações existentes entre usuários internos e externos. Outra característica é permitir que o usuário faça uma avaliação dos eventos passados em relação ao presente e projete situações futuras. E, por último, falam da importância da informação contábil para a tomada de decisão nas organizações. Entre os demonstrativos publicados pelas empresas, tem-se a Demonstração do Valor Adicionado (DVA).

De acordo com Santos e Hashimoto (2003), a DVA provém do Balanço Social e é por meio dela que é possível observar a riqueza gerada por uma empresa e como ela se formou. É possível identificar também quais foram os agentes que contribuíram para a criação dessa riqueza e qual foi a participação de cada um deles nesse processo. A DVA é, portanto, um demonstrativo contábil de caráter econômico que busca evidenciar a riqueza gerada pela empresa, bem como as razões pelas quais a empresa gerou esse valor (COSTA; GUIMARÃES; MELLO, 2013).

Cunha (2002) informa que, além de apresentar a riqueza gerada pela empresa, a DVA tem também como objetivo apresentar como essa riqueza foi distribuída aos agentes que contribuíram para a sua realização, sendo eles os empregados, o governo, os agentes financiadores e os acionistas. Portanto, a DVA está diretamente relacionada à Teoria da Divulgação proposta por Verrechia, visto que ela se apresenta como uma ferramenta de evidenciação das ações promovidas pela organização, tanto em ambiente interno quanto externo, por meio da distribuição da sua riqueza (CONCEIÇÃO et al., 2011).

No Brasil, a DVA passou a ser uma demonstração de caráter obrigatório para as empresas de capital aberto a partir das alterações instituídas pela Lei n. 11.638/07. A sua divulgação antes disso era voluntária. A obrigatoriedade de divulgação da DVA no Brasil surgiu em razão da convergência das normas contábeis brasileiras às normas contábeis internacionais e da criação do Comitê de Pronunciamentos Contábeis (CPC). Martins, Martins e Martins (2007) explicam que o CPC foi criado pelo Conselho Federal de Contabilidade (CFC), por meio da Resolução n. 1055/05 justamente com a função, entre outras, de concentrar a emissão das normatizações contábeis em convergência com as normas internacionais. 
Na literatura é possível encontrar algumas pesquisas que objetivam entender o que faz as organizações distribuírem mais ou menos da sua riqueza para os agentes econômicos: pessoal, governo, acionistas e financiadores. Alguns fatores que podem influenciar a distribuição de riqueza são os indicadores de desempenho. Existem três tipos de indicadores que são habitualmente utilizados na contabilidade: indicadores de liquidez, rentabilidade e estrutura de capital (BORTOLUZZI et al. 2011). Segundo Bezerra e Corrar (2006), os indicadores de desempenho costumam ser utilizados para realizar comparações entre organizações do mesmo segmento, ou então, até mesmo entre unidades da mesma empresa. De outro modo, eles poderão ser utilizados para avaliar a administração das estratégias da empresa (FISCHMANN; ZILBER, 1999). Mascarelo (2012) defende que os indicadores de liquidez, por exemplo, são influenciadores do valor adicionado distribuído aos empregados. Cunha (2002), no entanto, revela que as empresas que mais geram riquezas não são necessariamente aquelas que mais distribuem aos seus colaboradores. A autora ainda cita diferenças de distribuição entre os setores econômicos existentes.

Taiarol, Raimundini e Behr (2011), por meio de testes quantitativos e qualitativos, deixam claro a relação entre indicadores de desempenho internos como receita operacional e líquida com a geração e distribuição de riqueza. Os autores concluíram que os gastos com pessoal são um dos principais fatores para o aumento das receitas nas empresas estudadas. Diante de estudos como esse, sugere-se que há alguma relação entre os indicadores de desempenho econômico-financeiros e a geração e distribuição de riqueza. No entanto, muito se estuda sobre a relação desses indicadores com a distribuição de valor para pessoal, deixando de lado os demais agentes da DVA.

Assim, neste estudo pretende-se responder ao seguinte questionamento: qual a relação das variáveis de desempenho e de controle com a distribuição de riqueza gerada e distribuída pelas empresas listadas na BM\&FBovespa no período de 2010 a 2015? Consequentemente, objetiva-se avaliar a relação das variáveis de desempenho e de controle com a distribuição de riqueza gerada e distribuída pelas empresas dos diferentes setores da Bovespa.

Teoricamente, este trabalho contribuirá para a sociedade acadêmica e demais pesquisadores das áreas contábil, econômica e financeira, por meio de uma relação bastante robusta de variáveis de desempenho que estão correlacionados com a distribuição de valor adicionado. Do ponto de vista prático, poderá ser utilizado pelas empresas brasileiras como um banco de dados atualizado sobre as variáveis que influenciam na distribuição da sua própria riqueza. Por meio dessa análise, as empresas poderão até vislumbrar posicionamentos diferentes de organização e planejamento 
que influenciarão o seu desempenho mediante as variáveis apresentadas. Além disso, por meio da DVA a própria sociedade pode avaliar como e quanto as empresas contribuem para o desenvolvimento da região em que estão inseridas.

\section{FUNDAMENTAÇÃO TEÓRICA}

O Balanço Social é visto por Azevedo e Cruz (2007) como um instrumento vital de gestão para as empresas, pois a sua divulgação refletirá em questões como o crescimento da entidade, as estratégias a seguir e a continuidade da empresa no mercado, visto que os consumidores estão cada vez mais exigentes. A vertente do Balanço Social que trata do valor adicionado à sociedade é conhecida por Demonstração do Valor Adicionado (DVA).

A DVA busca fazer uma relação entre os aspectos econômicos e sociais de uma organização (CUNHA, 2002). Cosenza (2003) declara que a DVA é um relatório que foi criado para evidenciar o papel que as organizações têm na sociedade, demonstrando como ela influencia no desenvolvimento da comunidade. $\mathrm{O}$ valor adicionado que é calculado pelas empresas é parte integrante significativa de toda a riqueza gerada por um país (CUNHA; RIBEIRO; SANTOS, 2005). Machado et al. (2009) destacam justamente que a principal finalidade da DVA é demonstrar a riqueza gerada por uma organização e de que maneira ela distribuiu esse valor aos stakeholders, sendo eles os empregados, o governo, os financiadores e os acionistas.

As informações para a elaboração da Demonstração do Valor Adicionado devem ser extraídas da escrituração contábil, respeitando as normas vigentes e com base no princípio da competência, que determina que as receitas e despesas devem ser contabilizadas no período a que se referem (CAMARGO, 2010). Cosenza (2003) reforça que a estruturação da DVA deve seguir o método das partidas dobradas, contemplando uma parte que se refere às origens da riqueza e outra que se refere à distribuição desses recursos.

Uma parte da DVA, com base nas instruções do CPC 09, solicita que a empresa exiba de forma detalhada como procedeu a distribuição da riqueza adicionada, de maneira que os componentes sejam: pessoal (remuneração direta, benefícios e FGTS); impostos, taxas e contribuições (federais, estaduais e municipais); remuneração de capitais de terceiros (juros, aluguéis e outros) e remuneração de capitais próprios (juros sobre o capital próprio e dividendos, lucros retidos e prejuízos do exercício).

A Demonstração do Valor Adicionado tem grande relevância social, de modo que apresenta toda a riqueza gerada por uma organização e a maneira como ela foi 
distribuída. No entanto, é preciso esclarecer que as empresas estão situadas em um sistema econômico e que as alterações ocorridas nele podem afetar tanto a geração quanto a distribuição de valor pelas empresas (COSENZA; GALLIZO; JIMENEZ, 2002). O entendimento de variáveis de desempenho que possam estar diretamente correlacionadas com a distribuição da riqueza para os agentes como pessoal, governo, acionistas e financiadores é tema recorrente na literatura.

Dallabona, Kroetz e Mascarello (2014), por exemplo, buscaram identificar a relação existente entre os indicadores de desempenho empresarial e a distribuição do valor adicionado aos agentes. A conclusão da pesquisa foi que o ativo total e a receita são os indicadores que apresentam maior correlação com todos os agentes econômicos envolvidos. As variáveis de desempenho de uma empresa são encontradas a partir da análise das suas demonstrações contábeis e são de suma importância para avaliar o quão saudável ela está (MARION, 2011). O autor explica que essa análise é composta pelo tripé das análises de liquidez, endividamento e rentabilidade.

O estudo dos índices de liquidez de uma empresa visa demonstrar qual a situação financeira desta mediante os seus compromissos financeiros (ASSAF NETO, 2012). As pesquisas defendem que quanto maior o índice de liquidez de uma empresa, melhor ele é. No entanto, alguns estudiosos defendem que uma liquidez muito alta é tão ruim quanto uma liquidez baixa, pois representa má administração financeira e a empresa pode estar perdendo dinheiro com a inflação (MATARAZZO, 2010).

Os indicadores de endividamento são muito importantes pois demonstram a dependência do capital próprio mediante o capital de terceiros (IUDÍCIBUS, 2010). Para esse tipo de índice a avaliação feita é que quanto maior ele for, pior ele será (MATARAZZO, 2010). Já os indicadores de rentabilidade têm a finalidade de apresentar qual é o retorno recebido pela empresa em determinada situação. Tais indicadores nunca devem ser utilizados em números absolutos, pois isso não representará a situação da empresa. Sempre deve ser analisado de forma percentual qual é o retorno de lucro em relação às vendas, por exemplo (IUDÍCIBUS, 2010).

Além de variáveis de desempenho, citam-se variáveis de controle. O tempo de vida de uma empresa no mercado (idade) é uma variável que influencia no seu desempenho, e, portanto, na geração e distribuição de valor adicionado por ela (VOGT et al., 2013). De acordo com o estudo, há grande relação entre a idade da empresa com o retorno sobre o patrimônio líquido, o que indica que há maior desempenho organizacional nessas entidades. Além disso, Cancellier, Alberton e Barbosa (2011) defendem que o tempo é um fator determinante para a aprendizagem e a sobrevivência da organização. 
O tamanho das organizações, determinado pelo ativo total, pode ser influenciador do desempenho das suas atividades, na medida em que empresas maiores tendem a ser mais eficientes no uso dos seus ativos (VOGT et al., 2013). Na distribuição de valor adicionado, Mascarelo (2012) destaca que o tamanho das empresas é grande influenciador na distribuição de valor para o governo, e é considerado uma variável de desempenho.

Algumas pesquisas já vêm abordando o assunto em questão. Para exemplificar, foram extraídos alguns artigos da base de dados Scientific Periodicals Electronic Library (Spell), do período compreendido entre os anos 2000 e 2016, utilizando como palavras-chave demonstração do valor adicionado e variáveis de desempenho e controle. Autores como Cosenza e Kroetz (2003) destacam a importância da DVA para diversos grupos da sociedade. Os autores citam que, para os empregados, esse demonstrativo pode servir de base nas negociações salariais; o governo, por sua vez, pode avaliar por meio da carga tributária quais setores da economia são os maiores contribuintes da sua receita tributária. Os financiadores podem avaliar a saúde econômica da organização. Os acionistas conseguem realizar análises do retorno que estão obtendo com os seus investimentos. Os administradores utilizam a DVA como base para a tomada de decisão e a sociedade, por sua vez, consegue avaliar a representatividade das empresas para a geração de riqueza. No entanto, é preciso ressaltar que outros indicadores, como os de desempenho, podem estar relacionados com os números demonstrados na DVA. Uma organização com alta porcentagem de distribuição, a capital de terceiros, provavelmente apresenta também índices elevados de endividamento. É possível supor também que o acionista, além de buscar indicadores na DVA, verifique também os indicadores de rentabilidade do ativo rentabilidade do patrimônio líquido. Essas são algumas das hipóteses para as quais este estudo busca respostas.

Murro (2012) teve como objetivo estudar a associação de indicadores sociais internos e do valor adicionado ao corpo funcional e a rentabilidade em companhias abertas que publicam o Balanço Social. Para tal, o autor utilizou uma amostra composta por 20 empresas que continham todas as informações necessárias dos anos 2008, 2009 e 2010. Os resultados do estudo apontaram que a rentabilidade das empresas pode ser afetada pelos gastos com empregados.

O estudo de Berns e Flach (2014) objetivou analisar a distribuição setorial do valor adicionado a fim de verificar se houve impacto na destinação da riqueza após a crise financeira de 2008, e de constatar quais setores tiveram a maior fatia da DVA destinada ao governo. A amostra utilizada para a pesquisa compreendeu um total de 35 empresas, sendo 4 empresas de cada um dos 10 setores econômicos listados na 
BM\&FBovespa, com exceção do setor de Telecomunicações e de Petróleo, Gás e Biocombustíveis, entre os anos 2010 e 2011. Os resultados dessa pesquisa demonstram que dos 10 setores analisados, 8 apresentaram mudanças significativas na destinação de resultado. Além disso, constatou-se também que 6 setores, entre os 10, destinaram a maior parte do valor adicionado para o governo, por meio dos tributos. Por isso, foi possível concluir que houve impacto na destinação de riqueza após a crise financeira de 2008.

Analisar a distribuição de riqueza aos agentes econômicos de diferentes setores, no exercício de 2013, sobretudo em relação ao governo, foi o objetivo do estudo de Cardoso et al. (2015). Como amostra, o estudo utilizou-se de 63 empresas distribuídas entre 18 setores da economia brasileira, considerando as 5 primeiras empresas listadas na BM\&FBovespa, segundo a Revista Exame - Maiores e Melhores. Dos resultados encontrados, destacam-se alguns: entre os grupos da DVA para os quais é destinada a riqueza, o que mais recebeu foi o grupo de "Impostos, Taxas e Comunicações”. O setor que mais gerou riqueza no período estudado foi o setor de mineração, e o que menos gerou riqueza foi o setor de indústria da construção. Como resposta ao objetivo, conclui-se que entre os setores analisados, os que mais agregam valor para o governo são os setores de Telecomunicações, Energia e Indústria Digital, e os que menos agregam são os setores Farmacêutico e Indústria da Construção.

Na Polônia, Kijewska, Bluszcz e Sojda (2015) realizaram um estudo sobre a DVA das mineradoras e metalúrgicas daquele País. O objetivo do estudo era analisar as diferenças de valor adicionado para os agentes econômicos entre os dois setores e verificar os indicadores encontrados entre os anos 2011 e 2013. A amostra foi composta de duas empresas: uma de cada setor analisado. Para efetuar a pesquisa, os autores analisaram as Demonstrações do Valor Adicionado dos três anos e fizeram comparações. Como resultados da pesquisa, o primeiro fato encontrado foi que ambas as empresas apresentaram redução no valor adicionado e no PIB, mas isso se devia à situação geral da Polônia. Também foi possível identificar que as empresas possuíam políticas internas diferentes, visto que a mineradora gerou valor adicionado aos empregados na porcentagem de 45,45\% em 2011 e de 68,26\% em 2013, enquanto a metalúrgica apresentou 17,31\% e 32,06\% nos dois períodos.

\section{ASPECTOS METODOLÓGICOS}

A pesquisa caracteriza-se como quantitativa, descritiva e documental. A população envolve todas as empresas listadas na BM\&FBovespa, sendo que a amostra, 
após exclusão das empresas que não apresentaram dados suficientes para o cálculo dos indicadores de desempenho e valores provenientes da Demonstração do Valor Adicionado, compreende 268 empresas, sendo 58 do setor de Bens Industriais, 69 do Consumo Cíclico, 17 do Consumo não Cíclico, 32 de Materiais Básicos, 8 do setor de Petróleo, Gás e Biocombustíveis, 10 do setor da Saúde, 4 de Tecnologia da Informação, 7 do setor de Telecomunicações e 63 do setor de Utilidade Pública. Os cálculos deste estudo foram realizados por setor porque cada um deles é responsável por produtos e/ou serviços que são impactados de maneira diferente pelo ambiente econômico no qual estão inseridos.

Os dados para o cálculo da distribuição de valor adicionado foram extraídos do site da BM\&FBovespa no período entre 21 de dezembro de 2016 e 25 de março de 2017. Primeiramente, realizou-se a busca pelas Demonstrações de Valor Adicionado divulgadas entre 2010 e 2015. O período escolhido (entre 2010 e 2015) ocorreu pela disponibilidade de buscar as informações desejadas. É apenas a partir de 2010 que a DVA se apresenta no atual formato encontrado na BM\&FBovespa. Estudos com data anterior a 2010 reduziriam muito a amostra da pesquisa. E, no momento de conclusão desta pesquisa, as empresas ainda não haviam publicado seus relatórios financeiros de 2016, ficando o período da pesquisa restrito a 2015. No mês de abril de 2017 procedeu-se à coleta das informações necessárias para o cálculo dos indicadores na base de dados Economática, conforme indicado no Quadro 1:

Quadro 1 - Constructo indicadores de desempenho e de controle operacional

\begin{tabular}{|l|l|l|}
\hline \multicolumn{1}{|c|}{ Indicador } & \multicolumn{1}{|c|}{ Fórmula } & \multicolumn{1}{c|}{ Autores } \\
\hline Liquidez geral & $\begin{array}{l}\text { Ativo circulante + Realizável longo } \\
\text { prazo/Passivo circulante + Passivo } \\
\text { não circulante }\end{array}$ & $\begin{array}{l}\text { Assaf Neto (2012); Iudícibus } \\
\text { (2010); Matarazzo (2010). }\end{array}$ \\
\hline Liquidez corrente & Ativo circulante/Passivo circulante & $\begin{array}{l}\text { Assaf Neto (2012); Iudícibus } \\
\text { (2010); Matarazzo (2010). }\end{array}$ \\
\hline Liquidez seca & $\begin{array}{l}\text { Ativo circulante - Estoques - Despesas } \\
\text { antecipadas/Passivo circulante }\end{array}$ & $\begin{array}{l}\text { Assaf Neto (2012); Iudícibus } \\
\text { (2010); Matarazzo (2010). }\end{array}$ \\
\hline Endividamento & $\begin{array}{l}\text { Capital de terceiros (Passivo circulan- } \\
\text { te + Passivo não circulante) /Patrimô- } \\
\text { nio Líquido x 100 }\end{array}$ & $\begin{array}{l}\text { Assaf Neto (2012); Iudícibus } \\
\text { (2010); Matarazzo (2010). }\end{array}$ \\
\hline $\begin{array}{l}\text { Composição do endi- } \\
\text { vidamento }\end{array}$ & $\begin{array}{l}\text { Passivo circulante/Capital de terceiros } \\
\text { (Passivo circulante + Passivo não } \\
\text { circulante) x 100 }\end{array}$ & $\begin{array}{l}\text { Assaf Neto (2012); Iudícibus } \\
\text { (2010); Matarazzo (2010). }\end{array}$ \\
\hline Endividamento geral & $\begin{array}{l}\text { Capital de terceiros (Passivo circu- } \\
\text { lante + Passivo não circulante) / Total } \\
\text { do ativo }\end{array}$ & $\begin{array}{l}\text { Assaf Neto (2012); Iudícibus } \\
\text { (2010); Matarazzo (2010). }\end{array}$ \\
\hline
\end{tabular}




\begin{tabular}{|l|l|l|}
\hline \multicolumn{1}{|c|}{ Indicador } & \multicolumn{1}{|c|}{ Fórmula } & \multicolumn{1}{c|}{ Autores } \\
\hline $\begin{array}{l}\text { Imobilização do patri- } \\
\text { mônio líquido }\end{array}$ & $\begin{array}{l}\text { (Ativo total - Realizável em longo } \\
\text { prazo)/Patrimônio líquido x 100 }\end{array}$ & $\begin{array}{l}\text { Assaf Neto (2012); Iudícibus } \\
\text { (2010); Matarazzo (2010). }\end{array}$ \\
\hline $\begin{array}{l}\text { Imobilização dos re- } \\
\text { cursos não correntes }\end{array}$ & $\begin{array}{l}\text { (Ativo total - Realizável em longo } \\
\text { prazo)/Patrimônio líquido + Passivo } \\
\text { não circulante x 100 }\end{array}$ & $\begin{array}{l}\text { Assaf Neto (2012); Iudícibus } \\
\text { (2010); Matarazzo (2010). }\end{array}$ \\
\hline Rentabilidade do ativo & Lucro líquido/Ativo total & $\begin{array}{l}\text { Assaf Neto (2012); Iudícibus } \\
\text { (2010); Matarazzo (2010). }\end{array}$ \\
\hline $\begin{array}{l}\text { Rentabilidade do patri- } \\
\text { mônio líquido }\end{array}$ & Lucro líquido/Patrimônio líquido & $\begin{array}{l}\text { Assaf Neto (2012); Iudícibus } \\
\text { (2010); Matarazzo (2010). }\end{array}$ \\
\hline Idade & $\begin{array}{l}\text { Idade da cada empresa de acordo com } \\
\text { o site da BM\&FBovespa }\end{array}$ & $\begin{array}{l}\text { Ferreira, Marques e Barbosa (2007); } \\
\text { Vogt et al. (2013); Cancellier, Alber- } \\
\text { ton e Barbosa (2011); Fuch, Rosse- } \\
\text { to, Carvalho (2016). }\end{array}$ \\
\hline Tamanho & $\begin{array}{l}\text { Valor do ativo total de cada empresa } \\
\text { de acordo com a Economática }\end{array}$ & $\begin{array}{l}\text { Barbosa (2005); Cunha e Ribeiro } \\
\text { (2006); Gomes e Kruglianskas } \\
\text { (2009); Botelho, Maia e Pires } \\
\text { (2012); Mascarelo (2012); Vogt et } \\
\text { al. (2013). }\end{array}$ \\
\hline
\end{tabular}

Fonte: os autores.

Com exceção dos indicadores idade e tamanho, todos os demais foram calculados com a ajuda do Microsoft Excel. O indicador de controle idade foi obtido por meio de consulta ao site da BM\&FBovespa em cada empresa pesquisada. Primeiramente, foi realizada a coleta do ano de fundação da empresa e então a subtração do ano atual com o ano de fundação para encontrar a idade, e para o indicador de desempenho tamanho, foi utilizado o ativo total de cada empresa da amostra.

Para a análise dos dados, o estudo fez uso da estatística descritiva e correlação canônica. Esse método foi escolhido porque possibilita trabalhar com dois grupos de variáveis simultaneamente. O software Statistical Package for Social Sciences (SPSS) foi utilizado para cálculo desse método estatístico. Portanto, o objetivo desse modelo de análise é demonstrar a força da relação existente entre dois conjuntos de variáveis, as dependentes e as independentes.

No cálculo da correlação canônica as variáveis foram divididas em dois grupos, conforme demonstra o Quadro 2. Neste é possível identificar que as variáveis para o cálculo da correlação canônica são formadas pela distribuição do valor adicionado e por variáveis de desempenho. Ressalta-se que não foi considerado para o grupo da distribuição do valor adicionado a distribuição para outros, pois essa informação é divulgada por poucas empresas. Assim, a falta dessa informação na maioria das empresas não permitiria o cálculo da correlação canônica. Dessa maneira, a primeira coluna do Quadro 2 evidencia o grupo de variáveis, a segunda coluna demonstra o 
nome da variável por extenso e na terceira coluna tem-se as siglas das variáveis que foram utilizadas nos cálculos de correlação canônica:

Quadro 2 - Variáveis para cálculo da correção canônica

\begin{tabular}{|c|c|c|}
\hline Grupos & Variáveis & Siglas \\
\hline \multirow{5}{*}{$\begin{array}{l}\text { Distribuição do valor } \\
\text { adicionado }\end{array}$} & Distribuição total & DIS_TOT \\
\hline & Distribuição para pessoal & DIS_PES \\
\hline & $\begin{array}{l}\text { Distribuição para impostos, taxas e contribui- } \\
\text { ções }\end{array}$ & DIS_IMP \\
\hline & Distribuição para capital de terceiros & DIS_CAT \\
\hline & Distribuição para capital próprio & DIS_CAP \\
\hline \multirow{12}{*}{ Variáveis de desempenho } & Liquidez geral & LIQGER \\
\hline & Liquidez corrente & LIQCOR \\
\hline & Liquidez seca & LIQSEC \\
\hline & Endividamento & END \\
\hline & Composição do endividamento & COMEND \\
\hline & Endividamento geral & ENDGER \\
\hline & Imobilização do patrimônio líquido & IMOPL \\
\hline & Imobilização dos recursos não correntes & IMORNC \\
\hline & Rentabilidade do ativo & RENTA \\
\hline & Rentabilidade do patrimônio líquido & RENTPL \\
\hline & Idade da empresa & IDADE \\
\hline & Tamanho da empresa & TAM \\
\hline
\end{tabular}

Fonte: os autores.

Por meio da combinação linear entre os dois conjuntos de variáveis é possível determinar se há relação estatística ou não. Para Epley (2009), o modelo de correlação canônica pode ser escrito de forma geral pela Equação 1:

$$
(\mathrm{c} 1, \mathrm{c} 2, \ldots, \mathrm{cq})=(\mathrm{p} 1, \mathrm{p} 2, \ldots, \mathrm{pp})
$$

Na qual:

c: grupo de variáveis 1 (no caso da presente pesquisa, as variáveis de distribuição de valor adicionado);

p: grupo de variáveis 2 (no caso da presente pesquisa, os indicadores de desempenho e de controle);

q e p: número máximo de variáveis X e Y, respectivamente. 
Para a análise, se o coeficiente de correlação estiver entre 0,91 e 1,00 a força de associação das variáveis é muito forte. Se estiver entre 0,71 e 0,90 a força de associação é alta. Entre 0,41 e 0,70 a associação é moderada. A força de associação será pequena, mas definida, se estiver entre 0,21 e 0,40. No entanto, poderá ser leve, ou quase imperceptível se a correlação estiver entre 0,01 e 0,20.

\section{ANÁLISE DOS RESULTADOS}

Esta seção contempla a descrição e análise dos dados realizados por aplicação do teste de correlação canônica. Por meio da aplicação da correlação canônica, calcularam-se o coeficiente de correlação e o nível de significância do grupo de variáveis de desempenho em relação à distribuição de valor adicionado das empresas por setor econômico. Primeiramente, apresenta-se o modelo de correlação que apresentou o maior coeficiente de correlação entre os grupos de variáveis analisadas. Após, mostram-se os coeficientes de significância de cada grupo estudado.

A correlação canônica foi calculada por setor de atuação (bens industriais, consumo cíclico, consumo não cíclico, materiais básicos, petróleo, gás e biocombustíveis, saúde, tecnologia da informação, telecomunicações e utilidade pública). O primeiro setor a ser estudado foi o de bens industriais. Observou-se que houve significativa correlação canônica da primeira combinação linear, indicando que existe uma força de associação moderada entre as variáveis do modelo. Na Tabela 1 verificam-se os coeficientes das variáveis canônicas provenientes da relação entre as variáveis de desempenho e a distribuição de valor adicionado do setor de bens industriais.

Para este estudo serão utilizados apenas os coeficientes descritos na primeira coluna, visto que esta representa a primeira combinação linear, ou seja, aquela que apresenta maior correlação entre as cinco combinações lineares calculadas. 
Tabela 1 - Coeficientes para as variáveis canônicas das variáveis de desempenho e distribuição do valor adicionado das empresas do setor de bens industriais

\begin{tabular}{|c|c|c|c|c|c|c|}
\hline \multirow{2}{*}{ Grupos } & \multirow{2}{*}{ Variável } & \multicolumn{5}{|c|}{ Combinações lineares } \\
\hline & & 1 & 2 & 3 & 4 & 5 \\
\hline \multirow{12}{*}{ 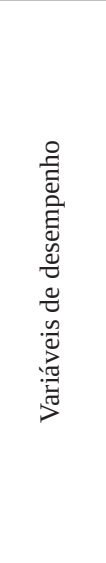 } & LIQGER & 0,197 & 0,346 & 0,065 & 0,526 & 0,557 \\
\hline & LIQCOR & $-2,050$ & $-0,772$ & $-0,072$ & 0,960 & $-0,314$ \\
\hline & LIQSEC & 1,094 & 0,227 & $-0,146$ & $-1,398$ & 0,542 \\
\hline & END & $-1,762$ & $-0,206$ & 0,156 & $-2,493$ & $-4,596$ \\
\hline & COMEND & 0,038 & $-0,329$ & 0,117 & $-0,549$ & $-0,512$ \\
\hline & ENDGER & $-0,636$ & 0,937 & $-0,042$ & $-0,002$ & $-0,038$ \\
\hline & IMOPL & 1,889 & 0,072 & $-0,008$ & 2,469 & 4,951 \\
\hline & IMORNC & $-0,127$ & 0,151 & $-0,556$ & 0,561 & 0,121 \\
\hline & RENTA & $-0,446$ & 1,054 & 0,564 & $-0,596$ & $-0,169$ \\
\hline & RENTPL & 0,149 & $-0,133$ & 0,173 & $-0,091$ & 0,342 \\
\hline & IDADE & 0,015 & 0,015 & $-0,048$ & $-0,440$ & $-0,910$ \\
\hline & TAM & 0,194 & 0,154 & $-0,735$ & $-0,811$ & $-0,148$ \\
\hline \multirow{5}{*}{ 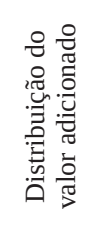 } & DIS_TOT & 1,044 & 29,144 & 18,572 & $-43,354$ & $-31,772$ \\
\hline & DIS_PES & $-2,426$ & $-20,072$ & $-8,291$ & 21,762 & 11,052 \\
\hline & DIS_IMP & $-0,553$ & $-3,939$ & $-7,805$ & 8,792 & 4,685 \\
\hline & DIS_CAT & 1,333 & $-3,011$ & $-3,813$ & 5,139 & 6,597 \\
\hline & DIS_CAP & $-0,055$ & $-2,829$ & 0,475 & 8,182 & 10,798 \\
\hline
\end{tabular}

Fonte: os autores.

Ao relacionar as variáveis positivas de desempenho com as variáveis positivas de distribuição do valor adicionado da primeira coluna, observa-se que há uma correlação diretamente proporcional entre as variáveis de desempenho (liquidez geral (LIQGER), liquidez seca (LIQSEC), composição do endividamento (COMEND), imobilização do patrimônio líquido (IMOPL), rentabilidade do patrimônio líquido (RENTPL), idade e tamanho (TAM)) e as variáveis de distribuição (distribuição total (DIS_TOT) e distribuição para capital de terceiros (DIS_CAT)). Dessa forma, quanto maiores forem a liquidez geral (LIQGER), liquidez seca (LIQSEC), composição do endividamento (COMEND), imobilização do patrimônio líquido (IMOPL), rentabilidade do patrimônio líquido (RENTPL), idade e tamanho (TAM), maiores serão a distribuição total (DIS_TOT) e a distribuição para capital de terceiros (DIS_CAT), e vice-versa (FÁVERO et al., 2009).

A maior associação entre as variáveis positivas se encontra entre a imobilização do patrimônio líquido $(1,889)$ e a distribuição para capital de terceiros $(1,333)$. A imobilização do patrimônio líquido demonstra qual a porcentagem do capital próprio que não está em giro, ou seja, que está imobilizada (IUDÍCIBUS, 2010). Empresas 
que não estão em plena capacidade produtiva apresentam a imobilização do patrimônio líquido alta. Desse modo, é possível supor que organizações que estão nessa condição necessitam de empréstimos e financiamentos para voltar a produzir, o que, por sua vez, gera pagamento de juros, um subgrupo da distribuição para capital de terceiros.

De forma semelhante, pode-se observar relação diretamente proporcional também entre as variáveis negativas de desempenho: liquidez corrente (LIQCOR), endividamento (END), endividamento geral (ENDGER), imobilização dos recursos não correntes (IMORNC) e rentabilidade do ativo (RENTA), com as variáveis negativas de distribuição: distribuição para pessoal (DIS_PES), distribuição para impostos (DIS_ IMP) e distribuição para capital próprio (DIS_CAP). Assim, quanto maiores/menores forem os primeiros, maiores/menores também serão os segundos, respectivamente.

A maior associação entre as variáveis negativas se encontra entre a liquidez corrente $(-2,050)$ e a distribuição para pessoal $(-2,426)$. Se o índice de liquidez corrente for maior que um, há um capital circulante líquido positivo, significa que na maioria das vezes a empresa está bem financeiramente, ou seja, que tem capacidade de pagamento (ASSAF NETO, 2012). Para estar bem financeiramente, essa empresa precisa estar em plena capacidade produtiva, o que significa que ela precisa de funcionários para trabalhar. Pressupõe-se, então, que é dessa maneira que a liquidez corrente está diretamente relacionada com a distribuição para pessoal. Se a liquidez corrente aumenta, aumenta também a distribuição para pessoal, se a liquidez corrente diminui, diminui, assim, também a distribuição para pessoal.

Na Tabela 2 verificam-se os coeficientes das variáveis canônicas provenientes da relação entre as variáveis de desempenho e a distribuição de valor adicionado do setor de consumo cíclico. No cálculo de significância, observou-se que houve associação moderada entre as variáveis do modelo. 
Tabela 2 - Coeficientes para as variáveis canônicas das variáveis de desempenho e distribuição do valor adicionado das empresas do setor de consumo cíclico

\begin{tabular}{|c|c|c|c|c|c|c|}
\hline \multirow{2}{*}{ Grupos } & \multirow{2}{*}{ Variável } & \multicolumn{5}{|c|}{ Combinações lineares } \\
\hline & & 1 & 2 & 3 & 4 & 5 \\
\hline \multirow{12}{*}{ 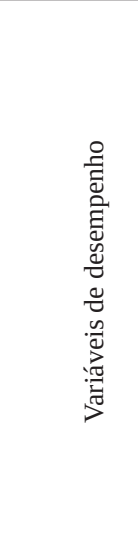 } & LIQGER & 0,170 & 0,719 & $-0,873$ & 0,791 & 1,189 \\
\hline & LIQCOR & 0,573 & $-1,169$ & $-2,001$ & $-2,844$ & $-3,631$ \\
\hline & LIQSEC & $-0,661$ & 0,635 & 2,319 & 2,506 & 2,902 \\
\hline & END & 0,331 & $-0,057$ & 1,809 & 0,011 & 1,785 \\
\hline & COMEND & $-0,097$ & $-0,757$ & 0,033 & $-0,145$ & $-0,440$ \\
\hline & ENDGER & $-0,021$ & 0,059 & 0,167 & $-0,240$ & 0,392 \\
\hline & IMOPL & $-0,454$ & 1,107 & $-2,279$ & $-1,614$ & $-1,324$ \\
\hline & IMORNC & 0,000 & $-0,025$ & $-0,179$ & 0,122 & $0-, 215$ \\
\hline & RENTA & 0,007 & 0,109 & $-0,263$ & 0,216 & $-0,321$ \\
\hline & RENTPL & $-0,121$ & 1,228 & $-0,690$ & $-1,673$ & 0,105 \\
\hline & IDADE & $-0,142$ & $-0,553$ & $-0,448$ & $-0,238$ & 0,443 \\
\hline & TAM & $-1,003$ & $-0,003$ & $-0,056$ & 0,111 & 0,067 \\
\hline \multirow{5}{*}{ 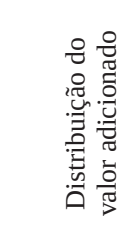 } & DIS_TOT & $-353,040$ & 127,225 & 312,394 & 411,892 & $-1848,747$ \\
\hline & DIS_PES & 94,515 & $-41,821$ & $-82,982$ & $-101,368$ & 494,852 \\
\hline & DIS_IMP & 156,078 & $-55,339$ & $-125,863$ & $-179,663$ & 771,325 \\
\hline & DIS_CAT & 31,025 & $-11,681$ & $-34,882$ & $-47,104$ & 200,020 \\
\hline & DIS_CAP & 72,539 & $-19,177$ & $-70,473$ & $-85,339$ & 388,043 \\
\hline
\end{tabular}

Fonte: os autores.

Ao relacionar as variáveis de desempenho com a distribuição do valor adicionado da primeira coluna, observa-se que há uma correlação diretamente proporcional entre as variáveis positivas de desempenho (liquidez geral (LIQGER), liquidez corrente (LIQCOR), endividamento (END), imobilização dos recursos não correntes (IMORNC) e rentabilidade do ativo (RENTA)) e as variáveis positivas de distribuição (distribuição para pessoal (DIS_PES), distribuição para impostos, taxas e contribuições (DIS_IMP), distribuição para capital de terceiros (DIS_CAT) e distribuição para capital próprio (DIS_CAP)).

Dessa forma, quanto maiores forem os coeficientes da liquidez geral (LIQGER), liquidez corrente (LIQCOR), endividamento (END), imobilização dos recursos não correntes (IMORNC) e rentabilidade do ativo (RENTA), maiores serão a distribuição para pessoal (DIS_PES), distribuição para impostos, taxas e contribuições (DIS_IMP), distribuição para capital de terceiros (DIS_CAT) e distribuição para capital próprio (DIS_CAP), e vice-versa. A maior associação de variáveis positivas pode ser encontrada entre a variável liquidez corrente e a variável distribuição para impostos, taxas e contribuições $(156,078)$. Assaf Neto (2012) diz que se o índice de 
liquidez corrente for maior que um, há um capital circulante líquido positivo, o que reflete boa situação financeira da empresa. Uma situação financeira estável pode representar que a empresa está em plena capacidade produtiva. Quanto mais se produz, mais impostos são pagos. Por isso se presume que há forte associação entre o índice de liquidez corrente e a distribuição de valor para impostos, taxas e contribuições.

De forma semelhante, pode-se observar relação diretamente proporcional também entre as variáveis negativas de desempenho (liquidez seca (LIQSEC), composição do endividamento (COMEND), endividamento geral (ENDGER), imobilização do patrimônio líquido (IMOPL), rentabilidade do patrimônio líquido (RENTPL), idade e tamanho (TAM)) e a variável negativa distribuição total (DIS_TOT).

Assim, os resultados são diretamente proporcionais, quanto maior for uma das variáveis de desempenho, maior será a distribuição total, nesse caso. A maior associação de variáveis negativas pode ser encontrada entre a variável tamanho $(-1,003)$ e a variável distribuição total (-353,04). Vogt et al. (2013) afirmam que quanto maior o porte da empresa, melhor será o desempenho desta, visto que o tamanho reflete na eficiência dos gestores. Assim é possível explicar a forte associação da variável tamanho com a distribuição de valor total. Quanto maior a empresa, mais geração de riqueza, quanto menor o tamanho, menor geração de riqueza.

Na sequência demonstram-se os resultados para o setor de consumo não cíclico. Destaca-se que duas combinações lineares apresentaram significância. Por meio da Tabela 3, demonstram-se os coeficientes das variáveis canônicas provenientes da relação entre as variáveis de desempenho e a distribuição de valor adicionado do setor de consumo não cíclico: 
Tabela 3 - Coeficientes para as variáveis canônicas das variáveis de desempenho e distribuição do valor adicionado das empresas do setor de consumo não cíclico

\begin{tabular}{|c|c|c|c|c|c|c|}
\hline \multirow{2}{*}{ Grupos } & \multirow{2}{*}{ Variável } & \multicolumn{5}{|c|}{ Combinações lineares } \\
\hline & & 1 & 2 & 3 & 4 & 5 \\
\hline \multirow{12}{*}{ 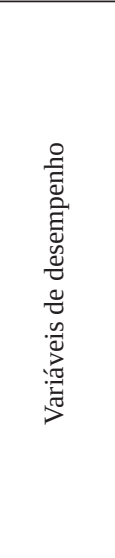 } & LIQGER & $-0,102$ & $-0,890$ & 0,314 & $-1,576$ & 1,552 \\
\hline & LIQCOR & 0,006 & 1,231 & 2,741 & 0,373 & $-0,663$ \\
\hline & LIQSEC & 0,107 & $-0,773$ & $-2,209$ & 0,491 & $-0,729$ \\
\hline & END & $-0,006$ & 3,128 & 1,939 & $-4,398$ & $-1,889$ \\
\hline & COMEND & 0,036 & 0,165 & 0,135 & 1,081 & $-0,592$ \\
\hline & ENDGER & $-0,077$ & 0,303 & 0,179 & $-0,826$ & 0,359 \\
\hline & IMOPL & $-0,002$ & $-2,698$ & $-2,368$ & 3,578 & 1,508 \\
\hline & IMORNC & $-0,031$ & 0,437 & $-0,148$ & $-0,189$ & 0,561 \\
\hline & RENTA & $-0,001$ & $-0,117$ & $-0,391$ & 0,322 & $-0,695$ \\
\hline & RENTPL & $-0,013$ & 0,405 & $-0,433$ & $-0,676$ & $-0,017$ \\
\hline & IDADE & 0,001 & $-0,618$ & $-0,675$ & $-0,092$ & $-0,420$ \\
\hline & TAM & $-1,012$ & $-0,153$ & 0,040 & $-0,005$ & 0,044 \\
\hline \multirow{5}{*}{ 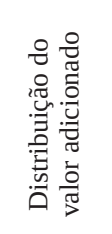 } & DIS_TOT & 2,885 & $-74,749$ & 113,588 & $-65,316$ & $-17,204$ \\
\hline & DIS_PES & $-1,890$ & 28,855 & $-42,385$ & 28,049 & 7,602 \\
\hline & DIS_IMP & $-0,626$ & 13,716 & $-22,433$ & 10,358 & 4,279 \\
\hline & DIS_CAT & $-1,302$ & 30,248 & $-44,742$ & 23,480 & 5,579 \\
\hline & DIS_CAP & $-0,303$ & 7,230 & $-12,653$ & 8,105 & 0,781 \\
\hline
\end{tabular}

Fonte: os autores.

Ao relacionar as variáveis de desempenho com a distribuição do valor adicionado da primeira coluna, observa-se que há uma correlação diretamente proporcional entre as variáveis positivas de desempenho (liquidez corrente (LIQCOR), liquidez seca (LIQSEC), composição do endividamento (COMEND) e idade) e a variável positiva de distribuição total (DIS_TOT). Dessa forma, quanto maiores/menores forem a liquidez corrente (LIQCOR), liquidez seca (LIQSEC), composição do endividamento (COMEND) e idade, maior/menor também será a distribuição total (DIS_TOT).

A maior associação de variáveis positivas está entre a variável liquidez seca $(0,107)$ e a distribuição total $(2,885)$. O indicador de liquidez seca demonstra a capacidade de pagamento da empresa somente com a utilização das contas do disponível e valores a receber, sem considerar os estoques (IUDÍCIBUS, 2010). Assim, espera-se que empresas que possuem bons índices de liquidez seca apresentem também bons resultados nas suas atividades, pois isso representa boa situação financeira. Situação financeira estável reflete em capacidade produtiva, e, por sua vez, em geração de riqueza. Dessa maneira, é possível perceber forte associação do indicador de desempenho liquidez seca com a distribuição de valor adicionado total. 
Da mesma maneira, é possível observar relação diretamente proporcional também entre as variáveis negativas de desempenho (liquidez geral (LIQGER), endividamento (END), endividamento geral (ENDGER), imobilização do patrimônio líquido (IMOPL), imobilização dos recursos não correntes (IMORNC), rentabilidade do ativo (RENTA), rentabilidade do patrimônio líquido (RENTPL) e tamanho (TAM)) e as variáveis negativas de distribuição para pessoal (DIS_PES), distribuição para impostos, taxas e contribuições (DIS_IMP), distribuição para capital de terceiros (DIS_CAT) e distribuição para capital próprio (DIS_CAP). A maior associação de variáveis negativas está entre a variável liquidez geral $(-0,102)$ e a distribuição para pessoal $(-1,890)$. O índice de liquidez geral demonstra quanto há de bens e direitos no ativo circulante e no realizável em longo prazo para cada um real de dívida (ASSAF NETO, 2012). Sendo um indicador que demonstra a saúde financeira da empresa em longo prazo, e estando ele acima de 1, o que é considerado bom, é possível interpretar que a empresa está em plena capacidade produtiva, e por isso necessita de pessoal para executar as tarefas. Dessa maneira, é possível supor que quanto maior a liquidez geral, maior é também a distribuição para pessoal, e quanto menor a liquidez geral, menor a distribuição para pessoal.

Na Tabela 4, verificam-se os coeficientes das variáveis canônicas provenientes da relação entre as variáveis de desempenho e a distribuição de valor adicionado do setor de materiais básicos. Quanto às combinações lineares desse setor, foi possível observar que existe uma força de associação entre as variáveis do modelo.

Tabela 4 - Coeficientes para as variáveis canônicas das variáveis de desempenho e distribuição do valor adicionado das empresas do setor de materiais básicos

\begin{tabular}{|c|c|c|c|c|c|c|}
\hline \multirow{2}{*}{ Grupos } & \multirow{2}{*}{ Variável } & \multicolumn{5}{|c|}{ Combinações lineares } \\
\hline & & 1 & 2 & 3 & 4 & 5 \\
\hline \multirow{12}{*}{ 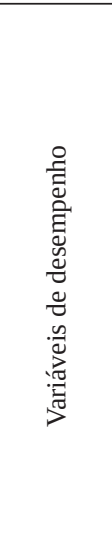 } & LIQGER & $-0,056$ & 0,368 & $-0,022$ & $-0,264$ & 0,523 \\
\hline & LIQCOR & 6,920 & $-66,850$ & 9,302 & $-8,499$ & $-115,425$ \\
\hline & LIQSEC & $-6,816$ & 66,993 & $-10,104$ & 8,574 & 115,269 \\
\hline & END & $-0,929$ & 4,581 & $-0,311$ & 8,027 & $-1,059$ \\
\hline & COMEND & 0,003 & 0,271 & $-0,313$ & 0,286 & $-0,324$ \\
\hline & ENDGER & $-0,065$ & 0,276 & $-0,455$ & $-0,413$ & $-0,087$ \\
\hline & IMOPL & 0,863 & $-4,111$ & 0,556 & $-7,536$ & 0,781 \\
\hline & IMORNC & $-0,026$ & $-0,087$ & 0,050 & 0,059 & $-0,260$ \\
\hline & RENTA & $-0,785$ & 6,344 & 3,630 & 7,535 & $-2,129$ \\
\hline & RENTPL & $-0,762$ & 6,143 & 3,970 & 7,854 & $-2,027$ \\
\hline & IDADE & $-0,057$ & $-0,400$ & $-0,321$ & 0,718 & 0,704 \\
\hline & TAM & $-0,997$ & 0,213 & $-0,154$ & $-0,133$ & $-0,271$ \\
\hline
\end{tabular}




\begin{tabular}{|c|c|c|c|c|c|c|}
\hline \multirow{2}{*}{ Grupos } & \multirow{2}{*}{ Variável } & \multicolumn{5}{|c|}{ Combinações lineares } \\
\hline & & 1 & 2 & 3 & 4 & 5 \\
\hline \multirow{5}{*}{ 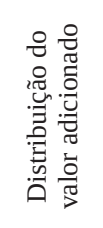 } & DIS_TOT & 0,064 & $-1,610$ & 4,263 & 2,190 & $-15,216$ \\
\hline & DIS_PES & $-0,122$ & $-1,640$ & $-0,766$ & $-0,659$ & 4,005 \\
\hline & DIS_IMP & 0,090 & 1,746 & $-2,502$ & 0,326 & 4,853 \\
\hline & DIS_CAT & $-1,137$ & 1,848 & $-1,985$ & $-1,702$ & 8,070 \\
\hline & DIS_CAP & $-0,663$ & 0,775 & $-0,956$ & $-1,204$ & 8,416 \\
\hline
\end{tabular}

Fonte: os autores.

Ao relacionar as variáveis de desempenho com a distribuição do valor adicionado da primeira coluna, observa-se que há uma correlação diretamente proporcional entre as variáveis positivas de desempenho (liquidez corrente (LIQCOR), composição do endividamento (COMEND) e imobilização do patrimônio líquido (IMOPL)) e as variáveis de distribuição total (DIS_TOT) e distribuição para impostos, taxas e contribuições (DIS_IMP). Dessa forma, quanto maiores/menores forem a liquidez corrente (LIQCOR), composição do endividamento (COMEND) e imobilização do patrimônio líquido (IMOPL), maiores/menores serão a distribuição total (DIS_TOT) e a distribuição para impostos, taxas e contribuições (DIS_IMP).

A maior associação de variáveis positivas está entre a variável liquidez corrente $(6,920)$ e a distribuição para impostos, taxas e contribuições $(0,090)$. Assaf Neto (2012) diz que se o índice de liquidez corrente for maior que um, há um capital circulante líquido positivo, o que reflete boa situação financeira da empresa. Uma situação financeira estável pode representar que a empresa está em plena capacidade produtiva. Quanto mais se produz, mais impostos são pagos. Por isso se presume que há forte associação entre o índice de liquidez corrente e a distribuição de valor para impostos, taxas e contribuições.

De forma semelhante, pode-se observar relação diretamente proporcional também entre as variáveis de desempenho negativas (liquidez geral (LIQGER), liquidez corrente (LIQSEC), endividamento (END), endividamento geral (ENDGER), imobilização dos recursos não correntes (IMORNC), rentabilidade do ativo (RENTA), rentabilidade do patrimônio líquido (RENTPL), idade e tamanho (TAM)) e as variáveis negativas de distribuição para pessoal (DIS_PES), distribuição para capital de terceiros (DIS_CAT) e distribuição para capital próprio (DIS_CAP). Assim, quanto maiores/menores forem os primeiros, maiores/menores serão os segundos, respectivamente.

A maior associação de variáveis negativas está entre a variável liquidez seca $(-6,816)$ e a distribuição para capital de terceiros $(-1,137)$. Para o cálculo do índice de liquidez seca, os estoques não são considerados. Assim, há uma posição mais conservadora da liquidez da empresa, e faz com que esse índice seja preferido por 
financiadores (IUDÍCIBUS, 2010). Dessa maneira, bons índices de liquidez seca são facilitadores para a tomada de empréstimo e financiamentos, que, por sua vez, irão refletir na distribuição para capital de terceiros no momento do pagamento dos juros.

Na sequência apresentam-se os coeficientes da correlação canônica para o setor de petróleo, gás e biocombustíveis. O coeficiente de correlação canônica indica que existe uma força de associação muito forte entre as variáveis do modelo. Na Tabela 5 verificam-se os coeficientes das variáveis canônicas provenientes da relação entre as variáveis de desempenho e a distribuição de valor adicionado desse setor.

Ao relacionar as variáveis de desempenho com a distribuição do valor adicionado da primeira coluna, observa-se que há uma correlação diretamente proporcional entre as variáveis positivas de desempenho (liquidez geral (LIQGER), liquidez seca (LIQSEC), endividamento geral (ENDGER), imobilização do patrimônio líquido (IMOPL), imobilização dos recursos não correntes (IMORNC), rentabilidade do ativo (RENTA)) e a variável positiva de distribuição total (DIS_TOT). Dessa forma, quanto maiores/menores forem a liquidez geral (LIQGER), liquidez seca (LIQSEC), endividamento geral (ENDGER), imobilização do patrimônio líquido (IMOPL), imobilização dos recursos não correntes (IMORNC), rentabilidade do ativo (RENTA), maior/ menor será a distribuição total (DIS_TOT).

Tabela 5 - Coeficientes para as variáveis canônicas das variáveis de desempenho e distribuição do valor adicionado das empresas do setor de petróleo, gás e biocombustíveis

\begin{tabular}{|c|c|c|c|c|c|c|}
\hline \multirow{2}{*}{ Grupos } & \multirow{2}{*}{ Variável } & \multicolumn{5}{|c|}{ Combinações lineares } \\
\hline & & 1 & 2 & 3 & 4 & 5 \\
\hline \multirow{12}{*}{ 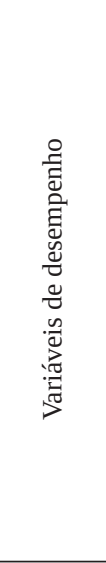 } & LIQGER & 0,002 & 2,232 & $-1,729$ & 1,933 & 0,485 \\
\hline & LIQCOR & $-0,352$ & 47,086 & $-23,319$ & 49,150 & 36,202 \\
\hline & LIQSEC & 0,351 & $-49,263$ & 25,560 & $-51,307$ & $-36,752$ \\
\hline & END & $-0,180$ & $-16,377$ & 8,185 & $-34,479$ & 6,320 \\
\hline & COMEND & $-0,004$ & $-0,541$ & $-0,645$ & 0,021 & $-0,097$ \\
\hline & ENDGER & 0,019 & 1,142 & $-1,955$ & $-0,667$ & 1,317 \\
\hline & IMOPL & 0,177 & 16,089 & $-8,118$ & 34,118 & $-6,877$ \\
\hline & IMORNC & 0,003 & $-0,070$ & $-0,096$ & 0,002 & 0,309 \\
\hline & RENTA & 0,166 & 10,382 & $-16,940$ & $-5,104$ & 5,149 \\
\hline & RENTPL & $-0,150$ & $-8,320$ & 16,357 & 7,263 & $-5,453$ \\
\hline & IDADE & $-0,013$ & $-0,505$ & 1,317 & $-0,223$ & $-1,281$ \\
\hline & TAM & $-0,994$ & $-0,288$ & $-0,475$ & $-0,289$ & 0,467 \\
\hline \multirow{5}{*}{ 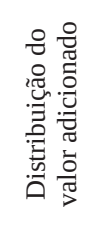 } & DIS_TOT & 5,110 & $-683,229$ & $-4206,820$ & 288,486 & $-771,759$ \\
\hline & DIS_PES & $-1,252$ & 106,930 & 620,103 & $-41,716$ & 106,586 \\
\hline & DIS_IMP & $-3,383$ & 398,934 & 2508,129 & $-168,837$ & 466,551 \\
\hline & DIS_CAT & $-1,308$ & 153,125 & 931,178 & $-67,842$ & 171,663 \\
\hline & DIS_CAP & $-0,952$ & 130,155 & 788,096 & $-54,877$ & 144,582 \\
\hline
\end{tabular}


A maior associação de variáveis positivas está entre a variável liquidez seca $(0,351)$ e a distribuição total $(5,110)$. O indicador de liquidez seca demonstra a capacidade de pagamento da empresa somente com a utilização das contas do disponível e valores a receber, sem considerar os estoques (IUDÍCIBUS, 2010). Assim, espera-se que empresas que possuem bons índices de liquidez seca apresentem também bons resultados nas suas atividades, pois isso representa boa situação financeira. Situação financeira estável reflete em capacidade produtiva, e, por sua vez, em geração de riqueza. Dessa maneira, é possível perceber forte associação do indicador de desempenho liquidez seca com a distribuição de valor adicionado total.

De forma semelhante, pode-se observar relação diretamente proporcional também entre as variáveis negativas de desempenho (liquidez corrente (LIQCOR), endividamento (END), composição do endividamento (COMEND), rentabilidade do patrimônio líquido (RENTPL), idade e tamanho (TAM)) e as variáveis negativas de distribuição (distribuição para pessoal (DIS_PES), distribuição para impostos, taxas e contribuições (DIS_IMP), distribuição para capital de terceiros (DIS_CAT) e distribuição para capital próprio (DIS_CAP)), sendo que a maior associação de variáveis negativas está entre a variável tamanho $(-0,994)$ e a distribuição para impostos, taxas e contribuições $(-3,383)$.

Vogt et al. (2013) afirmam que quanto maior o porte da empresa, melhor será o desempenho desta, visto que o tamanho reflete na eficiência dos gestores. Assim, é possível explicar a forte associação da variável "tamanho" com a distribuição de valor para impostos, taxas e contribuições. Quanto maior a empresa, mais geração de riqueza e maior o pagamento de impostos. Os coeficientes das variáveis canônicas provenientes da relação entre as variáveis de desempenho e a distribuição de valor adicionado do setor de saúde são expostos na Tabela 6 .

Ao analisar as variáveis de desempenho com a distribuição do valor adicionado da primeira coluna, observa-se que há uma correlação diretamente proporcional entre as variáveis positivas de desempenho (liquidez geral (LIQGER), liquidez corrente (LIQCOR), composição do endividamento (COMEND), endividamento geral (EDGER), imobilização do patrimônio líquido (IMOPL), imobilização dos recursos não correntes (IMORNC), rentabilidade do ativo (RENTA), rentabilidade do patrimônio líquido (RENTPL), idade e tamanho (TAM)) e as variáveis de distribuição (distribuição para pessoal (DIS_PES), distribuição para impostos, taxas e contribuições (DIS_IMP), distribuição para capital de terceiros (DIS_CAT) e distribuição para capital próprio (DIS_CAP)), sendo que a maior associação de variáveis positivas está entre a variável liquidez corrente $(1,625)$ e a distribuição para pessoal $(29,608)$. 
Tabela 6 - Coeficientes para as variáveis canônicas das variáveis de desempenho e distribuição do valor adicionado das empresas do setor de saúde

\begin{tabular}{|c|c|c|c|c|c|c|}
\hline \multirow{2}{*}{ Grupos } & \multirow{2}{*}{ Variável } & \multicolumn{5}{|c|}{ Combinações lineares } \\
\hline & & 1 & 2 & 3 & 4 & 5 \\
\hline \multirow{12}{*}{ 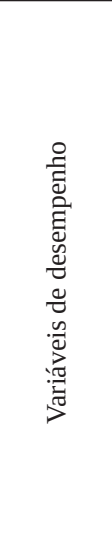 } & LIQGER & 0,127 & $-0,414$ & $-0,752$ & 0,341 & 0,454 \\
\hline & LIQCOR & 1,625 & 0,096 & $-4,973$ & 0,499 & $-4,183$ \\
\hline & LIQSEC & $-1,527$ & $-0,032$ & 5,363 & 0,297 & 4,644 \\
\hline & END & $-0,292$ & 2,677 & 0,420 & 3,094 & 1,816 \\
\hline & COMEND & 0,016 & 0,349 & 1,175 & 1,063 & $-0,393$ \\
\hline & ENDGER & 0,241 & $-0,736$ & $-0,300$ & 1,557 & 0,934 \\
\hline & IMOPL & 0,283 & $-2,789$ & $-0,685$ & $-2,443$ & $-1,384$ \\
\hline & IMORNC & 0,125 & 0,235 & $-0,538$ & 0,442 & 0,591 \\
\hline & RENTA & 0,024 & $-0,929$ & 0,720 & 1,055 & 0,205 \\
\hline & RENTPL & 0,112 & $-0,646$ & 0,196 & 0,867 & 0,062 \\
\hline & IDADE & 0,162 & $-0,172$ & $-0,380$ & $-0,316$ & 0,669 \\
\hline & TAM & 1,098 & $-0,125$ & 0,096 & 0,767 & 0,455 \\
\hline \multirow{5}{*}{ 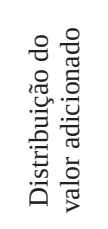 } & DIS_TOT & $-66,456$ & 75,871 & 305,903 & 73,790 & $-111,575$ \\
\hline & DIS_PES & 29,608 & $-33,246$ & $-131,869$ & $-33,933$ & 46,348 \\
\hline & DIS_IMP & 23,234 & $-25,959$ & $-105,603$ & $-24,019$ & 37,840 \\
\hline & DIS_CAT & 17,192 & $-19,240$ & $-80,074$ & $-18,340$ & 31,771 \\
\hline & DIS_CAP & 17,334 & $-20,621$ & $-79,151$ & $-19,415$ & 29,689 \\
\hline
\end{tabular}

Assaf Neto (2012) afirma que índices de liquidez corrente maior que 1 indicam que a empresa está bem financeiramente. É possível admitir que uma organização precisa ter capacidade produtiva para ter saúde financeira, o que traz, portanto, a necessidade de mão de obra para executar as tarefas. Assim, identifica-se a relação entre liquidez corrente e distribuição para pessoal: quando uma aumenta a outra também aumenta, e vice-versa.

Dessa forma, quanto maiores/menores forem a liquidez geral (LIQGER), liquidez corrente (LIQCOR), composição do endividamento (COMEND), endividamento geral (EDGER), imobilização do patrimônio líquido (IMOPL), imobilização dos recursos não correntes (IMORNC), rentabilidade do ativo (RENTA), rentabilidade do patrimônio líquido (RENTPL), idade e tamanho (TAM), maiores/menores serão a distribuição para pessoal (DIS_PES), distribuição para impostos, taxas e contribuições (DIS_IMP), distribuição para capital de terceiros (DIS_CAT) e distribuição para capital próprio (DIS_CAP).

É possível observar também relação diretamente proporcional entre as variáveis negativas de desempenho (liquidez seca (LIQSEC) e endividamento (END)) 
e a variável de distribuição total (DIS_TOT), sendo que a maior associação de variáveis negativas está entre a variável liquidez seca $(-1,527)$ e a distribuição total $(-66,456)$. Segundo Iudícibus (2010), os estoques não são considerados para o cálculo do indicador de liquidez seca, o que demonstra, portanto, a capacidade de pagamento da empresa somente com as contas do disponível e contas a receber. Assim, um bom índice de liquidez seca pode indicar capacidade produtiva, e, portanto, geração de riqueza.

Na Tabela 7 verificam-se os coeficientes das variáveis canônicas provenientes da relação entre as variáveis de desempenho e a distribuição de valor adicionado dos setores de tecnologia da informação e telecomunicações. Destaca-se que uma combinação linear indicou que existe uma força de associação muito forte entre as variáveis do modelo.

Tabela 7 - Coeficientes para as variáveis canônicas das variáveis de desempenho e distribuição do valor adicionado das empresas dos setores de tecnologia da informação e telecomunicações

\begin{tabular}{|c|c|c|c|c|c|c|}
\hline \multirow{2}{*}{ Grupos } & \multirow{2}{*}{ Variável } & \multicolumn{5}{|c|}{ Combinações lineares } \\
\hline & & 1 & 2 & 3 & 4 & 5 \\
\hline \multirow{12}{*}{ 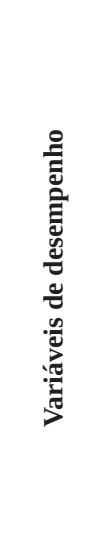 } & LIQGER & 0,119 & $-0,682$ & 0,237 & $-0,522$ & $-0,334$ \\
\hline & LIQCOR & 0,151 & $-3,123$ & $-10,106$ & 11,521 & $-24,868$ \\
\hline & LIQSEC & $-0,135$ & 2,887 & 10,626 & $-11,356$ & 25,872 \\
\hline & END & $-0,710$ & $-9,976$ & $-0,124$ & $-68,487$ & 7,200 \\
\hline & COMEND & $-0,051$ & $-0,008$ & 0,178 & 0,933 & 2,647 \\
\hline & ENDGER & 0,072 & $-0,723$ & 0,831 & $-0,541$ & 0,589 \\
\hline & IMOPL & 0,751 & 8,038 & $-3,999$ & 62,774 &,- 733 \\
\hline & IMORNC & 0,068 & $-0,037$ & $-0,071$ & $-0,147$ & $-1,832$ \\
\hline & RENTA & 0,011 & 0,029 & $-0,043$ & $-0,610$ & $-0,558$ \\
\hline & RENTPL & 0,018 & $-1,933$ & $-4,221$ & $-5,785$ & 6,654 \\
\hline & IDADE & 0,107 & $-0,901$ & $-0,523$ & 0,614 & 0,661 \\
\hline & TAM & $-0,929$ & $-0,476$ & 0,177 & 0,270 & $-0,372$ \\
\hline \multirow{5}{*}{ 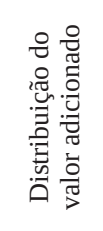 } & DIS_TOT & 0,632 & $-0,664$ & 0,217 & 14,336 & $-71,562$ \\
\hline & DIS_PES & $-0,297$ & $-0,688$ & $-2,231$ & $-0,304$ & 7,105 \\
\hline & DIS_IMP & $-1,022$ & 1,551 & 1,577 & $-5,964$ & 41,784 \\
\hline & DIS_CAT & $-0,408$ & $-0,405$ & 0,664 & $-7,473$ & 22,411 \\
\hline & DIS_CAP & $-0,041$ & 0,470 & $-0,518$ & $-5,015$ & 13,124 \\
\hline
\end{tabular}

Ao relacionar as variáveis de desempenho com a distribuição do valor adicionado da primeira coluna, observa-se que há uma correlação diretamente proporcional entre as variáveis positivas de desempenho (liquidez geral (LIQGER), liquidez corrente (LIQCOR), endividamento geral (ENDGER), imobilização do patrimônio 
líquido (IMOPL), imobilização dos recursos não correntes (IMORNC), rentabilidade do ativo (RENTA), rentabilidade do patrimônio líquido (RENTPL) e idade) e a variável positiva de distribuição total (DIS_TOT), sendo que a maior associação de variáveis positivas está entre a variável imobilização do patrimônio líquido $(0,751)$ e a distribuição total $(0,632)$.

A imobilização do patrimônio líquido demonstra qual a porcentagem do capital próprio que não está em giro, ou seja, que está imobilizada (IUDÍCIBUS, 2010). Empresas que não estão em plena capacidade produtiva apresentam a imobilização do patrimônio líquido alta. Desse modo, é possível presumir que a geração de riqueza também está comprometida e, por consequência, a distribuição de valor adicionado total. Assim, quanto maiores/menores forem a liquidez geral (LIQGER), liquidez corrente (LIQCOR), endividamento geral (ENDGER), imobilização do patrimônio líquido (IMOPL), imobilização dos recursos não correntes (IMORNC), rentabilidade do ativo (RENTA), rentabilidade do patrimônio líquido (RENTPL) e idade, maior/menor será a distribuição total (DIS_TOT); elas são diretamente proporcionais.

De forma semelhante, pode-se observar relação diretamente proporcional também entre as variáveis negativas de desempenho (liquidez seca (LIQSEC), endividamento (END), composição do endividamento (COMEND) e tamanho (TAM)) e as variáveis de distribuição (distribuição para pessoal (DIS_PES), distribuição para impostos, taxas e contribuições (DIS_IMP), distribuição para capital de terceiros (DIS_CAT) e distribuição para capital próprio (DIS_CAP)), sendo que a maior associação de variáveis negativas está entre a variável tamanho $(-0,929)$ e a distribuição para impostos, taxas e contribuições $(-1,022)$. É comum que empresas de maior porte tenham um maior volume de atividades e por isso paguem mais impostos, taxas e contribuições do que empresas de menor porte, que possivelmente não apresentem tanta movimentação de produtos e serviços.

Os coeficientes das variáveis canônicas provenientes da relação entre as variáveis de desempenho e a distribuição de valor adicionado do setor de utilidade pública podem ser observados na Tabela 8. Ressalta-se que existe força de associação muito forte entre as variáveis: 
Tabela 8 - Coeficientes para as variáveis canônicas das variáveis de desempenho e distribuição do valor adicionado das empresas do setor de utilidade pública

\begin{tabular}{|c|c|c|c|c|c|c|}
\hline \multirow{2}{*}{ Grupos } & \multirow{2}{*}{ Variável } & \multicolumn{5}{|c|}{ Combinações lineares } \\
\hline & & 1 & 2 & 3 & 4 & 5 \\
\hline \multirow{12}{*}{ 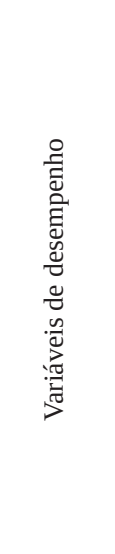 } & LIQGER & 0,014 & $-0,036$ & 0,029 & 0,124 & 0,148 \\
\hline & LIQCOR & $-2,166$ & $-45,163$ & 13,799 & $-79,025$ & 9,001 \\
\hline & LIQSEC & 2,166 & 45,066 & $-14,008$ & 78,762 & $-9,013$ \\
\hline & END & $-0,330$ & 4,975 & 0,270 & $-5,259$ & $-5,280$ \\
\hline & COMEND & $-0,020$ & 0,153 & $-0,537$ & $-0,396$ & 0,308 \\
\hline & ENDGER & 0,012 & 0,158 & 0,323 & 0,126 & $-0,430$ \\
\hline & IMOPL & 0,330 & $-5,076$ & $-0,448$ & 5,282 & 5,288 \\
\hline & IMORNC & 0,009 & 0,625 & 0,141 & 0,011 & 0,277 \\
\hline & RENTA & 0,016 & $-0,065$ & 1,019 & 0,077 & $-0,099$ \\
\hline & RENTPL & $-0,024$ & 0,512 & 0,346 & $-0,571$ & $-0,230$ \\
\hline & IDADE & $-0,024$ & 0,463 & $-0,110$ & $-0,170$ & 0,327 \\
\hline & TAM & $-0,994$ & 0,004 & 0,009 & 0,041 & 0,033 \\
\hline \multirow{5}{*}{ 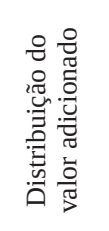 } & DIS_TOT & $-0,784$ & $-1,850$ & 5,763 & $-1,934$ & $-20,686$ \\
\hline & DIS_PES & $-0,750$ & $-0,170$ & $-1,179$ & $-0,490$ & 4,701 \\
\hline & DIS_IMP & 0,533 & 2,362 & $-3,962$ & 0,863 & 12,630 \\
\hline & DIS_CAT & 0,109 & 0,563 & $-1,435$ & 2,262 & 7,668 \\
\hline & DIS_CAP & 0,177 & 0,441 & $-0,654$ & 0,899 & 7,264 \\
\hline
\end{tabular}

Fonte: os autores.

Ao relacionar as variáveis de desempenho com a distribuição do valor adicionado da primeira coluna, observa-se que há uma correlação diretamente proporcional entre as variáveis positivas de desempenho (liquidez geral (LIQGER), liquidez seca (LIQSEC), endividamento geral (ENDGER), imobilização do patrimônio líquido (IMOPL), imobilização dos recursos não correntes (IMORNC) e rentabilidade do ativo (RENTA)) e as variáveis de distribuição (distribuição para impostos, taxas e contribuições (DIS_IMP), distribuição para capital de terceiros (DIS_CAT) e distribuição para capital de terceiros (DIS_CAP)), sendo que a maior associação de variáveis positivas está entre a variável liquidez seca $(2,166)$ e a distribuição para impostos, taxas e contribuições $(0,533)$.

Bons índices de liquidez seca podem indicar que a empresa está em plena capacidade produtiva, ou seja, produzindo e vendendo mercadorias e serviços a todo vapor. Como se sabe, toda movimentação de mercadorias e serviços sofre algum tipo de tributação. Dessa maneira, é possível concluir que a liquidez seca está diretamente relacionada com a distribuição para impostos, taxas e contribuições. Dessa forma, quanto maiores/menores forem a liquidez geral (LIQGER), liquidez seca (LIQSEC), 
endividamento geral (ENDGER), imobilização do patrimônio líquido (IMOPL), imobilização dos recursos não correntes (IMORNC) e rentabilidade do ativo (RENTA), maiores/menores também serão a distribuição para impostos, taxas e contribuições (DIS_IMP) e distribuição para capital de terceiros (DIS_CAT).

De forma semelhante, pode-se observar relação diretamente proporcional também entre as variáveis negativas de desempenho (liquidez corrente (LIQCOR), endividamento (END), composição do endividamento (COMEND), rentabilidade do patrimônio líquido (RENTPL), idade e tamanho (TAM)) e as variáveis negativas de distribuição (distribuição total (DIST_TOT) e distribuição para pessoal (DIS_PES)), sendo que a maior associação de variáveis negativas está entre a variável liquidez corrente $(-2,166)$ e a distribuição total $(-0,784)$. Bons índices de liquidez corrente podem representar boa situação financeira da organização, o que é um indício de que ela está gerando riqueza. Do contrário, índices de liquidez corrente baixos indicam que a empresa está passando dificuldades financeiras, sendo mais difícil gerar riqueza.

\section{CONCLUSÃO}

Neste estudo objetivou-se analisar a relação das variáveis de desempenho e de controle com a distribuição de riqueza gerada e distribuída pelas empresas listadas na BM\&FBovespa no período de 2010 a 2015, envolvendo uma amostra de 268 empresas divididas nos setores de bens industriais, consumo cíclico, consumo não cíclico, materiais básicos, petróleo, gás e biocombustíveis, saúde, tecnologia da informação, telecomunicações e utilidade pública. Os resultados demonstraram que algumas variáveis foram destaque na correlação com a distribuição de valor, com diferenças entre os setores econômicos. Para a distribuição total do valor adicionado se encontrou forte associação com as variáveis de desempenho: liquidez seca (setor de consumo não cíclico, petróleo, gás e biocombustíveis e de saúde), liquidez corrente (setor de utilidade pública), imobilização do patrimônio líquido (setor de tecnologia da informação e telecomunicações) e tamanho (consumo cíclico).

Descobriu-se também que a distribuição para pessoal tem forte associação com as variáveis de desempenho: liquidez corrente (setor de bens industriais e setor de saúde) e liquidez geral (setor de consumo não cíclico). Esse resultado converge com Mascarelo (2012), que afirma que a distribuição para empregados é influenciada pela liquidez corrente e pela liquidez seca. Marion (2011) destaca também que a liquidez corrente mais baixa pode representar uma administração financeira mais rigorosa, o que é muito importante em tempos de crise. 
A distribuição para impostos, taxas e contribuições possui forte associação com as variáveis de desempenho: liquidez corrente (setor de consumo cíclico e setor de materiais básicos), liquidez seca (setor de utilidade pública) e tamanho (setor de petróleo, gás e biocombustíveis e setores de tecnologia da informação e telecomunicações). A associação com a variável tamanho converge com o estudo de Vogt et al. (2013), no qual os autores mencionam que o porte da empresa está extremamente interligado com o desempenho dela. Em relação à distribuição para capital de terceiros, é possível observar que há forte associação entre as duas variáveis de desempenho: imobilização do patrimônio líquido (setor de bens industriais) e liquidez seca (setor de materiais básicos).

Conclui-se que há relação entre as variáveis de desempenho e de controle com a geração e distribuição de riqueza das empresas da BM\&FBovespa, sendo que algumas estão mais fortemente associadas do que outras. Quanto às variáveis de desempenho, os indicadores de liquidez (liquidez corrente, liquidez geral e liquidez seca) são os que aparecem com mais frequência associados à distribuição de valor. Dessa maneira, é possível observar que a relação dos indicadores econômico-financeiros apresenta importantes relações com a demonstração do valor adicionado, e isso implica que sejam realizadas constantes pesquisas relacionadas a esse tema, que pode e deve ter muita relevância na tomada de decisões por parte das empresas e também do governo. Além disso, por meio da DVA a própria sociedade pode avaliar como e quanto as empresas contribuem para o desenvolvimento da região em que estão inseridas. Para estudos futuros, sugere-se buscar outras variáveis de desempenho e variáveis econômicas que possam ter relação com a distribuição de valor, e analisar a distribuição de valor das empresas do setor financeiro, não englobadas neste estudo, por apresentarem uma estrutura de DVA diferente das demais empresas. Também devem ser levadas em consideração outras limitações deste estudo, como o período escolhido (2010 a 2015) e os métodos estatísticos utilizados na pesquisa.

\section{REFERÊNCIAS}

ASSAF NETO, A. Estrutura e análise de balanços. São Paulo: Atlas, 2012.

AZEVEDO, T. C.; CRUZ, C. F. Balanço social como instrumento para demonstrar a reponsabilidade social das entidades: uma discussão quanto à elaboração, padronização e regulamentação. Pensar Contábil, v. 8, n. 34, 2007. 
BERNS, J. C. G.; FLACH, L. Demonstração do Valor Adicionado: análise setorial da destinação da riqueza em empresas do novo mercado após a crise financeira de 2008. In: CONGRESSO ANPCONT, 8., 2014, Rio de Janeiro. Anais... Rio de Janeiro, 2014.

BEZERRA, F. A.; CORRAR, L. J. Utilização da análise fatorial na identificação dos principais indicadores para avaliação do desempenho financeiro: uma aplicação nas empresas de seguros. Revista Contabilidade e Finanças, v. 17, n. 42, p. 50-62, 2006.

BORTOLUZZI, S. C. et al. Avaliação de desempenho econômico-financeiro: uma proposta de integração de indicadores contábeis tradicionais por meio da metodologia multicritério de apoio à decisão construtivista (MCDA-C). Revista Alcance Eletrônica, v. 18, n. 2, p. 200-218, 2011.

CAMARGO, S. R. Demonstração do valor adicionado. 2010. 18 p. Monografia (Especialização em Auditoria e Gestão de Tributos)-Pontifícia Universidade Católica de Goiás, Goiânia, 2010.

CANCELLIER, E. L. P. L.; ALBERTON, A.; BARBOSA, A. S. Diferenças na atividade de monitoramento de informações do ambiente externo em pequenas e medias empresas: a influência do porte e da idade. Perspectivas em Ciência da Informação, v. 16, n. 2, p. 168-186, 2011.

CARDOSO, T. L. et al. Distribuição de riqueza aos agentes econômicos: um olhar sobre a DVA. In: CONGRESSO USP: CONTROLADORIA E CONTABILIDADE, 15., 2015, São Paulo. Anais... São Paulo, 2015.

CONCEIÇÃO, S. H. et al. Fatores determinantes no disclousure em Responsabilidade Social Corporativa (RSC): um estudo qualitativo e quantitativo com empresas listadas na Bovespa. Gest. Prod., v. 18, n. 3, p. 461-472, 2011.

COSENZA, J. P. A eficácia informativa da demonstração do valor adicionado. Revista Contabilidade \& Finanças, v. 14, n. SPE, p. 07-29, 2003.

COSENZA. J. P.; GALLIZO. J. L.; JIMENEZ. F. A participação dos agentes econômicos no valor adicionado: um estudo empírico na indústria siderúrgica brasileira no período 1996/2000. Contabilidade Vista e Revista, v. 13, n. 2, p. 37-99, 2002. 
COSENZA, J. P.; KROETZ, J. P. Considerações sobre a eficácia do valor adicionado para a mensuração do resultado econômico e social. In: CONVENÇÃO DE CONTABILIDADE DO RIO GRANDE DO SUL, 9., 2003, Gramado. Anais... Gramado, 2003.

COSTA, C. L. O.; GUIMARÃES, T. R.; MELLO, L. C. B. B. Os possíveis benefícios gerados pela obrigatoriedade da publicação da demonstração do valor adicionado pelas empresas de capital aberto. Revista de Contabilidade do Mestrado em Ciências Contábeis da UERJ, v. 18, n. 3, p. 77-93, 2013.

CUNHA, J. V. A. Demonstração do valor adicionado - DVA - Um instrumento de mensuração da distribuição da riqueza das empresas para os funcionários. 2002. 186 p. Dissertação (Mestrado em Controladoria e Contabilidade)-Universidade de São Paulo, São Paulo, 2002.

CUNHA, J. V. A.; RIBEIRO, M. S.; SANTOS, A. A demonstração do valor adicionado como instrumento de mensuração da distribuição da riqueza. Revista Contabilidade \& Finanças, v. 16, n. 37, p. 7-23, 2005.

DALLABONA, L. F.; KROETZ, M.; MASCARELLO, G. Relação entre os indicadores de desempenho e o valor adicionado distribuído aos agentes colaboradores de empresas listadas na BM\&FBovespa. Revista Catarinense de Ciência Contábil, v. 13, n. 39, p. 49-63, 2014.

EPLEY, D. US real estate agent in come and commercial/investment activities. Journal of Real Estate Research, v. 21, n.3 p. 221-244, 2009.

FÁVERO, L. P. et al. Análise de dados: modelagem multivariada para tomada de decisões. Rio de Janeiro: Campus, 2009.

FISCHMANN, A. A.; ZILBER, M. A. Utilização de indicadores de desempenho como instrumento de suporte à gestão estratégica. In. ENCONTRO DA ANPAD, 23., 1999, Foz do Iguaçú. Anais... Foz do Iguaçú, 1999.

GOMES, C. M.; KRUGLIANSKAS, I. A influência do porte no comportamento inovador da empresa. RAI: Revista de Administração e Inovação, v. 6, n. 2, p. 5-27, 2009.

IUDÍCIBUS, S. Análise de balanços. São Paulo: Atlas, 2010. 
KIJEWSKA, A.; BLUSZCZ, A.; SOJDA, A. Value added statement (VAS) of mining and metallurgical companies in Poland. Metalurgija, v. 54, i. 4, p. 737-740, 2015. MACHADO, A. E. et al. Destinação de riqueza aos empregados no Brasil: comparação entre empresas estatais e privadas do setor elétrico (2004-2007). Revista Contabilidade e Finanças, v. 20, n. 50, p. 110-122, 2009.

MACHADO, M. A. V.; MACEDO, M. A. S; MACHADO, M. R. Análise da Relevância do Conteúdo Informacional da DVA no Mercado Brasileiro de Capitais. Revista Contabilidade e Finanças, v. 26, p. 57-69, 2015.

MARION, J. C. Contabilidade Empresarial. São Paulo: Atlas, 2011.

MARTINS, E., MARTINS, V. A.; MARTINS, E. A. Normatização Contábil: Ensaio sobre a sua evolução e o papel do CPC. Revista de Informação Contábil, v. 1, n. 1, p. 7-30, 2007.

MASCARELO, G. Demonstração do valor adicionado: relação entre a distribuição de riqueza e indicadores de excelência empresarial de empresas listadas na BM\&FBovespa. 2012. 122 p. Monografia (Bacharelado em Ciências Contábeis)Universidade do Estado de Santa Catarina, 2012.

MATARAZZO, D. C. Análise financeira de balanços. São Paulo: Atlas, 2010.

MURRO, E. V. B. Indicadores sociais internos e de valor adicionado e rentabilidade: estudo em companhias abertas que publicam balanço social. 2012. 52 p. Monografia (Especialização em Controladoria)-Universidade Federal do Paraná, 2012.

SANTOS. A.; HASHIMOTO. H. Demonstração do Valor Adicionado: algumas considerações sobre a carga tributária. Revista de Administração, v. 38, n. 2, p. 153164, 2003.

TAIAROL, S. M.; RAIMUNDINI, S. L.; BEHR, A. Indicadores sociais internos e a geração de valor adicionado: uma análise da reação do Balanço Social e da Demonstração do Valor Adicionado em bancos brasileiros. Revista de Administração, Contabilidade e Sustentabilidade, v. 1, n. 2, p. 82-100, 2011.

VOGT, M. et al. Análise dos fatores que determinam o desempenho das empresas familiares brasileiras de capital aberto listadas na BM\&FBovespa pertencentes ao setor de consumo cíclico. In: CONGRESSO UFSC, 1., 2013, Florianópolis. Anais... Florianópolis, 2013. 


\title{
Como citar este artigo:
}

\begin{abstract}
ABNT
KIEFER, Débora Adriana Zwicker; DALLABONA, Lara Fabiana; KROETZ, Marilei. Relação das variáveis de desempenho e controle com a distribuição de riqueza das empresas listadas na BM\&FBovespa no período de 2010 a 2015. RACE, Revista de Administração, Contabilidade e Economia, Joaçaba: Ed. Unoesc, v. 17, n. 2, p. 475-506, maio/ago. 2018. Disponível em: <http://editora.unoesc.edu.br/index.php/ race>. Acesso em: dia/mês/ano.
\end{abstract}

\section{APA}

Kiefer, D. A. Z., Dallabona, L. F., \& Kroetz, M. (2018). Relação das variáveis de desempenho e controle com a distribuição de riqueza das empresas listadas na BM\&FBovespa no período de 2010 a 2015. RACE, Revista de Administração, Contabilidade e Economia, 17(2), 475-506. Recuperado em dia/mês/ano, de http://editora.unoesc.edu.br/index.php/race 
